\title{
EL PENSAMIENTO RELIGIOSO DE LUCAS ALAMÁN
}

Pablo Mijangos*

El conflicto entre liberales y conservadores marcó profundamente la vida política de México durante la primera mitad del siglo xix. Inmersos en un contexto generalizado de inestabilidad y crisis económica sin precedentes, ambos partidos se vieron obligados a imaginar el rostro que debía adquirir la nueva nación y a diseñar las instituciones necesarias para llevar sus proyectos a la práctica. El reto de crear una autoridad efectiva y duradera que fuera capaz de sustituir las estructuras del viejo Estado virreinal no era poca cosa, pero nos equivocaríamos si pensamos que la lucha de los partidos se debió solamente a sus diferencias en torno a formas de gobierno o sistemas económicos. Como señalan Charles A. Hale y Jean Meyer, la Iglesia católica fue el verdadero foco de combate político que opuso a liberales y conservadores. ${ }^{1}$ Pese a las numerosas e importantes coincidencias que de hecho llegaron a tener en sus programas, la división en materia religiosa fue tal que los llevó a enfrascarse en una terrible guerra civil en 1858, de la cual saldría victorioso el bando liberal casi diez años después. ¿Por qué la cuestión eclesiástica suscitó un conflicto de esta magnitud?

* Licenciado en Derecho, ITAM. Actualmente cursa el programa de maestría y doctorado en historia en la University de Texas en Austin.

${ }^{1}$ Charles A. Hale, El liberalismo mexicano en la época de Mora, 1972, México, Siglo XXI, p. 303-6; Jean Meyer, Historia de los cristianos en América Latina, siglos XIX y XX, 1991, México, Vuelta, p. 69-75. 
PABLO MIJANGOS

En este pequeño ensayo pretendo ofrecer una respuesta provisional a la pregunta que nos ocupa, analizando el pensamiento religioso de don Lucas Alamán (1792-1853), intelectual y político guanajuatense cuya obra constituye indudablemente la cima del conservadurismo mexicano. Terciario franciscano desde su juventud, Alamán fue visto por simpatizantes y adversarios como un defensor inquebrantable del catolicismo y del legado colonial. Más que por intransigencia o fanatismo, Alamán defendió a ultranza los derechos y la independencia de la Iglesia frente al nuevo Estado porque ésta ocupaba un lugar central en su visión de la sociedad y del destino del hombre. Nostálgico de una sociedad novohispana caracterizada por la omnipresencia social de las corporaciones eclesiásticas, el líder conservador pensaba que relegarlas a un papel secundario -como querían los liberales- llevaría a los habitantes de la nueva nación a un desastre individual y colectivo de dimensiones inimaginables. Religioso 'sin hazañería ni superstición’, Alamán veía en el cristianismo la única posibilidad de cumplimiento de la razón humana, y en la Providencia divina la mano que salvaría a México de la catástrofe en que se hallaba.

No está de más mencionar que con este trabajo también pretendo hacer una pequeña contribución a nuestro conocimiento del movimiento conservador, uno de los agujeros negros de la historiografía nacional. Salvo honrosas excepciones, los escasos trabajos que existen sobre los conservadores han tendido a considerarlos como representantes de oscuras fuerzas retrógradas y parasitarias, cuyo destino ineludible era sucumbir ante la impertérrita y digna mirada de sus adversarios liberales. Al menos hasta 1867, sin embargo, esta corriente política era una de las posibilidades históricas de México (tomando prestada la expresión de Edmundo O’Gorman), y sin duda tenía una base popular apreciable. A riesgo de quedarnos con una comprensión mutilada -y por tanto equívoca- de nuestro pasado, no podemos seguir dejando fuera de la escena a la mitad de sus protagonistas. Que éste sea un paso más, entonces, para entender a fondo el drama que subyace a toda nuestra historia política. 
LUCAS ALAMÁN

\section{Un católico ilustrado}

Lucas Ignacio Alamán y Escalada nació el 18 de octubre de 1792 en Guanajuato, ciudad que a finales del siglo XVIII era uno de los más prósperos y cultos centros urbanos de la Nueva España. Siguiendo la tradición, fue bautizado en la fe católica con el nombre del santo del día de su nacimiento, y con el de Ignacio, por la devoción que su familia profesaba al santo fundador de la Compañía de Jesús. Don Lucas era hijo de Vicente Alamán, un rico comerciante y minero estrechamente vinculado con la administración española, y de María Ignacia Escalada, quien descendía de los marqueses de San Clemente, 'una de las principales casas de Guanajuato'. ${ }^{2}$ Su medio hermano, Juan Bautista Arrechederreta, era uno de los canónigos de la catedral de la ciudad de México y con el tiempo llegaría a ser uno de los hombres con más influencia dentro de la jerarquía eclesiástica mexicana. ${ }^{3}$

Educado en un ambiente familiar profundamente religioso, Alamán destacó rápidamente por sus dotes intelectuales. La influencia del intendente Juan Antonio Riaño, quien poseía una de las mejores bibliotecas de la región, fue particularmente importante en su vida. Como recordaba uno de sus contemporáneos, Riaño “supo inspirar en él [...] una afición para el cultivo de las ciencias exactas y la lectura de los clásicos españoles, franceses y latinos". ${ }^{4}$ Sus primeros años, sin embargo, se verían perturbados por las preocupantes noticias que llegaban a su ciudad natal sobre el curso de los acontecimientos en Francia y su

2 Aquí nos basamos en la “Autobiografía de D. Lucas Alamán”, en Lucas Alamán, Documentos Diversos (Inéditos y muy raros), 1947, México, Jus, t. IV, p. 11-28; en Andrés Lira, "Lucas Alamán y la organización política de México”, en Lucas Alamán, 1997, México, Ediciones Cal y Arena, p. 12-4, y en Moisés González Navarro, El pensamiento político de Lucas Alamán, 1952, México, El Colegio de México, p. 11-21.

${ }^{3}$ José C. Valadés, Alamán. Estadista e historiador, 1977, México, UNAM, p. 17.

${ }^{4}$ Biografía necrológica del exmo. señor D. Lucas Alamán, 1853, México, Tipografía de R. Rafael, p. 3. 
PABLO MIJANGOS

temida influencia en los territorios españoles. En 1810 la Revolución llegaría a su puerta, y Alamán tendría la desdicha de presenciar con horror el sitio de la Alhóndiga de Granaditas y la muerte de muchos de sus amigos y parientes a manos de las huestes de Hidalgo. Al igual que otras familias de la alta sociedad guanajuatense, los Alamán se marcharían en diciembre de ese mismo año a la Ciudad de México en busca de seguridad para sus personas y bienes. Allí, el joven Lucas se inscribiría a los cursos de química, botánica y geometría ofrecidos por el renombrado Colegio de Minería, donde entraría en contacto con los más destacados representantes del pensamiento ilustrado en el México de principios del siglo XIX, como los célebres científicos Andrés Manuel del Río y Vicente Cervantes. En 1812 publicó en el Diario de México una defensa del sistema copernicano, e incluso se vería envuelto en líos con la Inquisición por habérsele demostrado la posesión de libros prohibidos, incidente del que salió adelante gracias a las poderosas influencias de su familia. ${ }^{5}$

Sin embargo, a diferencia de buena parte de sus colegas Alamán sumaría a su profundo estudio de las ciencias experimentales una extraordinaria devoción religiosa. Aunque la historiografía sobre su vida casi no le da importancia a este suceso, en febrero de 1810 Alamán recibió el hábito interior de la Tercera orden de franciscanos, ${ }^{6}$ cosa notable en una época en que buena parte de los intelectuales eran francmasones. La fraternidad seglar, que les exigía a sus miembros el requisito de mostrar 'limpieza' de sangre y 'buenas costumbres', 7 se había establecido en la Nueva España desde la primera mitad del siglo XVII, ${ }^{8}$ y su regla de vida abarcaba una variada gama de obligaciones, como la asistencia

${ }^{5}$ Moisés González Navarro, op. cit., p. 13.

${ }^{6}$ Lucas Alamán Papers, Benson Latin American Collection, University of Texas at Austin, n 44, "Patente del hábito del tercer orden de Penitencia de N.S.P.S. Francisco”, refrendada por Joaquín Antonio de Tramattegui.

${ }^{7}$ Este requisito se suprimió en 1813.

8 Juan B. Iguiniz, T.F., Breve Historia de la Tercera Orden Franciscana en la Provincia del Santo Evangelio de México desde sus Orígenes hasta Nuestros Días, 1951, México, Editorial Patria, p. 17. 
frecuente a la misa y a los ejercicios comunes de la hermandad, la austeridad en la comida y la bebida, el rezo de las horas canónicas, y la realización de obras de caridad. Al igual que otras confraternidades religiosas, la Tercera orden atravesó una época de dificultades durante las primeras décadas del siglo XIX, como consecuencia del embate de las reformas borbónicas y de la terrible crisis económica que enfrentó México a raíz de la guerra de Independencia. ${ }^{9}$ Juan B. Iguiniz, historiador de la Orden, refiere que en agosto de 1813, tres años después de que Alamán ingresara a sus filas, la Mesa directiva de la fraternidad se vio en la urgencia de suprimir incluso los gastos en velas y candiles para la procesión de Semana santa. ${ }^{10}$ Esta situación se agravaría unos años después con el ascenso del partido liberal al poder, en cuya visión de una sociedad secularizada no cabían las órdenes religiosas, “denunciadas como inútiles, improductivas y sobre todo peligrosas debido a su base popular". 11

En 1814, don Lucas iniciaría un largo viaje por Alemania, Francia, Italia e Inglaterra, donde conocería a notables hombres de ciencia y a los personajes más destacados de la Europa de la Restauración. A su regreso a México en 1819, Alamán iniciaría una brillante carrera política y empresarial. Tomando en cuenta los objetivos limitados de este trabajo, sólo tenemos espacio para resaltar algunos detalles de su biografía política, que acompaña en primera persona los acontecimientos más importantes de la vida nacional hasta 1853. Por el momento, basta decir que, además de ser el líder moral del partido conservador y secretario de gobierno, industria y relaciones exteriores en varias ocasiones, Alamán mantuvo en todo momento una relación intensa con la jerarquía eclesiástica de su tiempo. Su archivo personal está repleto de correspondencia con los obispos de todas las regiones del país, quienes acudían a él en busca de consejo y que en más de una ocasión le agradecieron

${ }^{9}$ Cfr. David Brading, Una Iglesia asediada: el obispado de Michoacán, 1749-1810, 1994, México, FCE, p. 150-69.

10 Juan B. Iguiniz, op. cit., p. 129.

11 Jean Meyer, op. cit., p. 63. 
PABLO MIJANGOS

con creces “sus desvelos por la patria y por la iglesia”. ${ }^{12}$ Asimismo, tuvo como preocupación constante la de establecer un vínculo estable con la curia romana y el papado, a quienes como encargado de la política exterior reafirmó en numerosas ocasiones “el catolicismo y la devoción a la Sede Apostólica de la Nación y Gobierno mexicanos”. 13

Como se afirma en una biografía publicada el año de su muerte, “en Alamán, el hombre privado guarda perfecta consonancia con el hombre público”. Sus contemporáneos, en efecto, no dejaron de resaltar la profunda religiosidad que lo definió hasta el último de sus días, signo de su pertenencia activa a la Tercera orden y a la Iglesia católica. Guillermo Prieto, un connotado miembro del partido liberal que se refugió en casa de Alamán durante la invasión norteamericana de 1847, recuerda en sus Memorias la ‘virtud, regularidad y orden’ que se vivía en casa de su anfitrión:

Se levantaba con la luz, y se lavaba y componía [...]. A las doce del día en punto se servía la comida a la que asistía toda la familia, haciendo los honores la señora Doña Narcisa su esposa, matrona adorable, de trato finísimo y de bondad angélica. Un sacerdote a quien llamaban tata padre, creo que hermano del Sr. Rodríguez Puebla, bendecía la mesa, y al concluir la comida rezaba el Pan nuestro besando el pan, y pidiendo la mano los criados a los amos. Se dormía la siesta y se dejaba el campo para el chocolate y el rezo del rosario a la oración. Yo merecía a esa familia la honra de que me admitiese en su seno, recibí distinciones del Sr. Alamán que me hacen grata su memoria, y ante todo, empeña mi gratitud el afecto con que siempre me trató y respetó mis opiniones, no obstante la acritud y suficiencia tonta con que a veces combatí las suyas. ${ }^{14}$

${ }^{12}$ Carta de Fr. José Ma. De Jesús, obispo de Monterrey, a Dn. Lucas Alamán, fechada el 23 de febrero de 1832, en Lucas Alamán, op. cit., p. 180.

${ }^{13}$ Carta de Lucas Alamán al Papa León XII, diciembre de 1823, citada por Roberto Gómez Ciriza, México ante la diplomacia vaticana, 1977, México, FCE, p. 124-5.

${ }^{14}$ Guillermo Prieto, Memorias de mis tiempos, 1948, México, Patria, t. II, p. 158-9. 
Y su hijo Juan resume mejor que nadie esa mezcla poco común de ilustración y catolicismo que caracterizó la vida íntima y social de nuestro personaje:

Criado Alamán en una capital de provincia y en un tiempo en que se atendía tanto á la educación religiosa de los niños, mamó con la leche la fe sincera de nuestros mayores, y profesando á cara descubierta la religión revelada, observaba las prácticas que prescribe. Así pues aquel hombre que había viajado tanto, que poseía una instrucción poco común, que había ocupado puestos tan elevados y que tenía por el aprecio general un lugar distinguido en la sociedad, frecuentaba los Santos Sacramentos, asistía con exactitud á las ceremonias de la Iglesia y observaba sus leyes hasta el punto de prevenir en la imprenta, cuando estaba dando á luz sus obras, que se limitasen los días festivos á formar la planta, sin tirar ejemplares, por ser esto obra servil. Practicaba estos actos de religión públicamente, no con la ostentación de un hipócrita, pero tampoco con la cobardía de un cristiano que se avergüenza de serlo, y sus enemigos jamás se atrevieron á burlarse de él por ellos, pues veían que su creencia estaba confirmada por sus costumbres [....$^{15}$

\section{Razón, cristianismo e Iglesia}

Como señala Moisés González Navarro, autor del más completo estudio sobre Alamán disponible hasta la fecha, don Lucas no llegó a expresar de manera sistemática su pensamiento filosófico. ${ }^{16}$ Antes que intelectual, Alamán era un estadista consumado, y por ello sus mayores obras no responden a necesidades teóricas, sino a la exigencia de debatir con sus adversarios el proyecto para construir la nueva nación. No

${ }^{15}$ Juan Alamán, Apuntes para la biografía del exmo. Sr. D. Lucas Alamán, 1854, México, Imprenta de José M. Lara, p. 53-4.

${ }^{16}$ Moisés González Navarro, op. cit., p. 29. 
PABLO MIJANGOS

obstante lo anterior, es posible entrever en sus escritos la influencia de un 'cristianismo ilustrado' surgido en la Europa del siglo XVIII como reacción contra el enciclopedismo, y cuyos objetivos eran distinguir la religión de la superstición y reafirmar la adhesión a las enseñanzas fundamentales de la Iglesia católica. ${ }^{17}$ Aunque Alamán no puede ser considerado un representante de esa dinámica cultura 'barroca posttridentina’ tan admirada por Brading, y mucho menos un entusiasta defensor de la religiosidad popular, en su obra intelectual y política pueden encontrarse los mejores argumentos ofrecidos por el catolicismo mexicano contra los desafíos que la nueva era de las revoluciones le planteaba.

En principio de cuentas, es importante recordar que en el siglo XVIII se vivió la más plena afirmación del racionalismo en la historia occidental. ${ }^{18}$ Para ese entonces, el gran movimiento cultural iniciado con el Renacimiento en Italia -que exaltaba el valor y el poder del hombre frente al teocentrismo de la Edad media- ya se había extendido a Francia, Holanda, Inglaterra y Alemania. Los descubrimientos científicos estaban a la orden del día y numerosos pensadores veían esos logros como una prueba irrefutable del potencial infinito de la razón humana. En los trabajos de Newton, por ejemplo, muchos veían un manual invaluable para descifrar la naturaleza matemática y lógica del Universo, cuyas últimas dimensiones y leyes podían ser calculadas. Los optimistas filósofos del siglo XVIII pensaban que si el hombre, aplicando la razón, era capaz de entender la naturaleza y someterla a sus propios fines, también podía tener en sus manos el secreto de la felicidad y el instrumento para alcanzarla. Un auténtico ilustrado, entonces, debía repudiar todo conocimiento que no estuviese definido o reconducido por la medida de la razón, pues cualquier creencia que

${ }^{17}$ Cfr. Paul Hazard, European Thought in the Eighteenth Century. From Montesquieu to Lessing, 1963, Cleveland, The World Publishing Company, p. 74-92.

${ }^{18}$ Cfr. Benno von Wiese, La cultura de la Ilustración, 1979, Madrid, Centro de Estudios Constitucionales, p. 21-75. 
fuera ajena a los dictados del intelecto humano -como la fe religiosano era sino un obstáculo para liberar al hombre de la superstición y la barbarie en que se hallaba. ${ }^{19}$

Aún a riesgo de ser repetitivos, debemos subrayar de nuevo que Lucas Alamán conocía con detalle el pensamiento de los más destacados filósofos de su tiempo. Había conocido personalmente a muchos de ellos, y era miembro de numerosas sociedades científicas de México, Estados Unidos y Europa. Lector incansable, guardaba en su biblioteca desde clásicos grecolatinos (Aristóteles, Cicerón), vidas de santos y 'opúsculos de los Santos Padres', hasta los trabajos históricos de Guizot y Gibbon, las obras completas de Bossuet y Mirabeau, El siglo de Luis XIV de Voltaire, El contrato social de Rousseau, los tratados económicos de Campomanes y el Genio del cristianismo de Chateubriand. ${ }^{20}$ Ese conocimiento detallado, sin embargo, no le llevó nunca a abrazar la causa del iluminismo. En su Defensa del ex-ministro de Relaciones D. Lucas Alamán, publicada en 1834 tras el ascenso al poder del liberal Valentín Gómez Farías, afirma claramente su condena al espíritu del siglo:

El proyecto que parece han intentado realizar el congreso y el gobierno de común acuerdo, es el establecimiento de un sistema extravagante tanto religioso como político, si sistema puede llamarse á la destrucción de todo cuanto existe, formado por la lectura de los desvaríos de Diderot y demás sofistas que se llamaron filósofos en el siglo pasado, cuyas obras no lee ya ningún hombre de juicio sino para admirar y compadecer los excesos á que conduce el extravío de la razón humana cuando

19 Respecto a este punto, un libro excelente es el de J.G.A. Pocock, Barbarism and Religion, 1999, Cambridge University Press.

${ }^{20}$ Lucas Alamán Papers, Benson Latin American Collection, University of Texas at Austin, n 359, "Copia del avalúo de los libros de la biblioteca del Sr. D. Lucas Alamán. México, septiembre 12 de 1853”, folios 210, 211, 213, 215, 219, 221, 224, 226, 227, 238, 247, 249, 252, 253, 254 у 270. 


\section{PABLO MIJANGOS}

dejando ésta la senda que le señalan las verdades reveladas, se obstina en tomar por única guía su loca y soberbia presunción. ${ }^{21}$

En un trabajo reciente, ${ }^{22}$ la historiadora María del Refugio González ha señalado que en el núcleo del pensamiento conservador de Alamán se haya la doctrina cristiana del 'pecado original': en vista de la fragilidad que existencialmente sufre la libertad del hombre para adherirse al bien que desea, cualquier esquema utópico que pretenda la regeneración del ser humano a partir de sí mismo conduce al desastre. Aún partiendo de esta premisa, don Lucas no es pesimista respecto al destino del hombre y a las posibilidades de su razón. Simplemente, deposita su confianza en la Providencia divina y en la Revelación, sin las cuales el intelecto y los esfuerzos humanos tienen poco futuro. Su Noticia de la vida y escritos del reverendo Padre Fray Manuel de San Juan Crisóstomo, donde comenta profusamente los sermones de este "carmelita de la provincia de San Alberto de México”, es clara al respecto:

Lejos de que exista esa guerra entre la revelación y la filosofía [...] al hombre pensador se le presentan unidas, y con un lazo tan estrecho, que siempre que se busca á la una, encuentra á las dos, dándose el ósculo de la más sincera fraternidad. Y [fray Manuel de San Juan Crisóstomo] pasa á probar la unión necesaria que hay entre ellas, con el paralelo que no podemos omitir en este lugar: “¿Qué es la revelación? La manifestación que Dios mismo se ha dignado hacer de su verdad y bondad, al grado que la razón no podía alcanzar por sí misma. ¿Qué es la filosofía? El conocimiento de lo verdadero y de lo bueno, derivado de la recta razón [...]. La doctrina que sólo le descubre

21 “Defensa del ex-ministro de Relaciones D. Lucas Alamán”, en Lucas Alamán, Documentos Diversos, 1942, México, Jus, t. III, p. 50-1.

${ }^{22}$ María del Refugio González, "El pensamiento de los conservadores mexicanos”, en Jaime E. Rodríguez O., ed., The Mexican and Mexican American Experience in the 19th Century, 1989, Tempe, Bilingual Press, p. 62. 
las verdades que puede alcanzar la razón, y muchas de las que no puede llegar á tocar, sin las fuerzas de la gracia.”23

La verdadera filosofía, añade Alamán, no puede encontrarse 'sino en el cristianismo’, ${ }^{24}$ el cual precisamente postula que Dios se ha acercado al hombre para colmar su razón y su afecto. Nuestro autor no se detiene, y afirma -siguiendo el Discurso sobre la unidad de Bossuet, el 'gran Pastor de la Iglesia francesa'- que es “en el cuerpo del Episcopado y de la Iglesia católica” donde puede encontrarse este 'espíritu de verdad', que 'prevalece allí siempre'. ${ }^{25}$ Si la Revelación y la Iglesia constituyen el espacio primordial para el cumplimiento de la razón y la libertad humanas, se concluye necesariamente que ambas son el centro alrededor del cual debe construirse la vida individual y social. Por ello, más que propugnar una renovación de las corruptas costumbres de la sociedad mexicana (por la cual estaban obsesionados algunos liberales, como Valentín Gómez Farías y Lorenzo de Zavala), ${ }^{26}$ Alamán va a dedicar sus mayores esfuerzos como pensador y político a reafirmar el papel central que la Iglesia había tenido -y debía tener-en la historia de su nación.

${ }^{23}$ Lucas Alamán, Noticia de la vida y escritos del reverendo padre Fray Manuel de San Juan Crisóstomo, carmelita de la provincia de San Alberto de México: del apellido Nájera en el siglo, 1854, México, Imprenta de Ignacio Cumplido, p. 49.

${ }^{24}$ Idem, p. 50.

${ }^{25}$ Idem, p. 46-7.

${ }^{26}$ William Fowler y Humberto Morales Moreno, "Introducción: una (re)definición del conservadurismo mexicano del siglo diecinueve”, en El Conservadurismo Mexicano en el siglo XIX (1810-1910), 1999, Puebla, Benemérita Universidad Autónoma de Puebla, p. 14. 
PABLO MIJANGOS

\section{La Providencia y la historia de México}

Lucas Alamán dedicó buena parte de su vida a escribir dos de las obras capitales de la historiografía mexicana del siglo XIX: las Disertaciones sobre la Historia de la República Mejicana desde la época de la conquista que los españoles hicieron a fines del siglo XV y principios del XVI de las islas y continente americano hasta la Independencia (1849), y la Historia de Méjico desde los primeros movimientos que prepararon su Independencia en el año de 1808 hasta la época presente (1852). En la escritura de ambos trabajos, en los que expone su visión de un México católico e hispánico, Alamán fue influido de nueva cuenta por la teología providencialista de Bossuet (en esta ocasión, por su Discours sur l'histoire universelle), para quien todos los acontecimientos de la historia responden a los designios de la voluntad divina. Lo señala claramente en la conclusión del tomo primero de la Historia:

Nosotros, guiados por las verdades de la fé cristiana, debemos reconocer y adorar en todos los sucesos humanos los decretos de la Providencia divina, que por fines inescrutables á nuestra limitada capacidad, deja en juego las pasiones de los hombres hasta que le conviene contenerlas, y desbaratando sus planes por los medios mas inopinados, sabe sacar bien del mal y todo lo conduce por senderos que no podemos penetrar.

Basado en estas ideas del obispo francés, Alamán presenta en las Disertaciones la historia de la Conquista como un suceso providencial por el cual se pudo establecer la Iglesia y difundir la civilización cristiana en México. ${ }^{27}$ A diferencia de Fray Servando Teresa de Mier y Carlos María de Bustamante, que habían identificado en las antiguas

${ }^{27}$ Libertad Gomis Iniesta, Hernán Cortés en la conciencia conservadora y liberal, 1963, México, Tesis de Maestría, UnAM, p. 35. 
culturas indígenas el origen profundo de la nación moderna -y que por lo mismo consideraban abominables los tres siglos de ilegítima ocupación española--, ${ }^{28}$ don Lucas va a subrayar una y otra vez que

La conquista, obra de las opiniones que dominaban en el siglo en que se ejecutó, ha venido á crear una nueva nación en la cual no queda rastro alguno de lo que antes existió: religión, lengua, costumbres, leyes, habitantes, todo es resultado de la conquista y en ella no deben examinarse los males pasajeros que causó, sino los efectos permanentes, los bienes que ha producido y que permanecerán mientras exista esta nación. ${ }^{29}$

Alamán no pretende ocultar la violencia y destrucción provocada por la conquista; la compara incluso con la entrada de los cruzados a Jerusalén, en la cual estos "pasaron a cuchillo a todos los habitantes de la ciudad [...] muchos días después de ganada”. 30 ¿Cuáles son, entonces, las consecuencias benéficas que esta cruenta e injusta guerra trajo a México? Alamán no duda en responder: "[la conquista] proporcionó a los pueblos oprimidos los consuelos de la religión cristiana y el apoyo y defensa de sus ministros”. ${ }^{31}$ En la séptima disertación, en la que explica profusamente el establecimiento de la Iglesia en México, llega a afirmar que

Nunca la religión se ha presentado bajo un aspecto tan venerable e imponente. Sus ministros, llenos del celo que animó a los apóstoles, despreciando todo interés y consideraciones mundanas, tomaron á su cargo la defensa del oprimido contra el opresor, del débil contra el fuerte, del extranjero y desconocido contra sus propios paisanos, con quienes los ligaban todos los

${ }^{28}$ David Brading, Los orígenes del nacionalismo mexicano, 1988, México, Era, p. 112.

${ }^{29}$ Lucas Alamán, Disertaciones, 1942, México, Jus, t. I, p. 120.

${ }^{30}$ Ibid.

${ }^{31}$ Idem, p. 26. 


\section{PABLO MIJANGOS}

lazos de la sangre y las preocupaciones y afectos de nacionalidad, é interponiendo la Cruz de Jesucristo entre la espada del conquistador y el pecho del vencido, hicieron que los habitantes del nuevo continente viesen en los ministros de la religión que se les predicaba, sus defensores, su amparo, sus guías y sus maestros en todas las artes y elementos de la vida civil. ${ }^{32}$

Así, don Lucas ve con ojos benignos la obra del conquistador Cortés, quien era el verdadero padre de la patria, el hombre elegido por la Providencia para llevar a buen término la cristianización del México antiguo. $^{33} \mathrm{Y}$ es que la conquista dio inicio a tres siglos de régimen colonial que, enmarcados por la omnipresencia social y económica de la Iglesia, habían sido benéficos para el país. Viendo al México derrotado, empobrecido y anárquico de la década de 1840, Alamán recordaba con nostalgia la prosperidad de la Nueva España, el verdadero y único pasado mexicano aceptable. ${ }^{34}$ En su Historia, Alamán alaba la obra de los últimos gobiernos borbónicos, aunque no deja de criticar sus restricciones a la industria y a la agricultura, y sobre todo, el hecho de haber expulsado tiránicamente a los jesuitas, a quienes consideraba "el grande antemural de que la Divina Providencia se sirvió para contener el protestantismo, lo que habían logrado especialmente por medio de la educación de la juventud”. ${ }^{35}$ En su opinión, fue la alta sociedad de las cortes europeas, 'contaminada' por las opiniones de "Voltaire, Rousseau, D’Alembert y los demás de aquella secta”, la que estuvo detrás de la expulsión, cuyo último y verdadero objetivo no era solamente acabar con la Compañía, sino 'derribar la autoridad pontificia'. ${ }^{36}$

En sus obras históricas, sin embargo, don Lucas no hace ninguna concesión a la religiosidad popular o al bajo clero secular. Los héroes de su relato son Cortés, los mendicantes del siglo XVI, los jesuitas y

${ }^{32}$ Lucas Alamán, Disertaciones, 1942, México, Jus, t. II, p. 116-7.

${ }^{33}$ Libertad Gomis Iniesta, op. cit., p. 196-7.

${ }^{34}$ David Brading, op. cit., p. 111.

${ }^{35}$ Lucas Alamán, Historia de Méjico, 1942, México, Jus, t. v, p. 796.

${ }^{36}$ Lucas Alamán, Disertaciones, 1942, México, Jus, t. III, p. 251-2. 
algunos obispos, pero sobre la importancia evangelizadora del culto a la Virgen de Guadalupe -quizá el más extendido entre la población novohispana- prefiere no pronunciarse. ${ }^{37} \mathrm{Al}$ igual que otros intelectuales de su tiempo, Alamán critica fuertemente la ignorancia del pueblo, y ve en sus expresiones religiosas una fe casi sentimental, reducida a 'meras prácticas exteriores':38

El pueblo, poco instruido en el fondo de la religión, hacía consistir ésta en gran parte en la pompa el culto, y careciendo de otras diversiones, se las proporcionaban las funciones religiosas, en las que especialmente en la Semana Santa, se representaban en multiplicadas procesiones, los misterios más venerables de la redención. Las fiestas de la Iglesia que debían ser todas espirituales, estaban pues convertidas todas en vanidad, habiendo muchos cohetes, danzas, loas, toros y juegos de gallos, y aún los vedados de naipes y otras diversiones, para celebrar á gran costa las solemnidades de los santos patronos de los pueblos, en cuyos objetos invertían los indios la mayor parte del fruto de su trabajo. ${ }^{39}$

De los ‘curas de los pueblos cortos’, nuestro autor sólo denuncia la impureza de sus costumbres y sus ‘propensiones materiales y groseras'. Es uno de estos curas ‘corrompidos', de hecho, el personaje más aborrecido por Alamán en su Historia: el padre Miguel Hidalgo y Costilla, a quien recuerda dirigiendo la turba que incendió la Alhóndiga de Granaditas en 1810.

En el plan de la revolución siguió Hidalgo las mismas ideas de los promovedores de la independencia en las juntas de Iturrigaray [...] como la imagen de Guadalupe es el objeto preferente del

${ }^{37}$ David Brading, Mexican Phoenix. Our Lady of Guadalupe: image and tradition across five centuries, 2001, Cambridge University Press, p. 265.

${ }^{38}$ Lucas Alamán, Historia de Méjico, 1942, México, Jus, t. I, p. 352.

${ }^{39}$ Idem, p. 69. 
PABLO MIJANGOS

culto de los mejicanos, la inscripción que se puso en las banderas de la revolución fue: "Viva la religión. Viva nuestra madre santísima de Guadalupe. Viva Fernando VII. Viva la América y muera el mal gobierno": pero el pueblo que se agolpaba a seguir esta bandera, simplificaba la inscripción y el efecto de ella gritando solamente "Viva la Virgen de Guadalupe y mueran los gachupines.” ¡Reunión monstruosa de la religión con el asesinato y el saqueo, grito de muerte y de desolación, que habiéndolo oído mil y mil veces en los primeros días de mi juventud, después de tantos años resuena todavía en mis oídos con un eco pavoroso. ${ }^{40}$

Y es que al llegar al año 1810 el rumbo de su Historia cambia radicalmente. Si hasta ese momento todo parecía ser llevado a buen cauce por la Divina providencia, de ahí en adelante da la impresión de que México fue condenado a padecer un 'día fatídico' tras otro. Como agudamente observa Charles A. Hale, no era a la Independencia en sí misma a la que Alamán ponía en entredicho. ${ }^{41}$ Para Don Lucas, no hubo un solo movimiento emancipador en México, sino dos: el primero iniciado por Miguel Hidalgo en 1810, que se desintegró hacia 1820, y el segundo encaminado por en 1821 por Agustín de Iturbide. La diferencia entre ambos no puede ser mayor: mientras que el cura de Dolores era tan sólo un demagogo que había excitado a la turba con las doctrinas aberrantes de los filósofos franceses, Iturbide había tenido el olfato político para intuir que la separación de España tenía que ser un 'efecto natural' del transcurso de los siglos, y no un producto de la furia revolucionaria. ${ }^{42}$ ¿Cuál fue el mayor pecado del Hidalgo y consecuentemente de sus apologistas? El haber querido eliminar de la noche a la mañana lo que a la Providencia le había tomado tres siglos construir: una nación católica e hispánica. Alamán llegaría a afirmar (irónicamente, por supuesto) que la ocupación de la ciudad de México el 16 de septiembre

${ }^{40}$ Idem, p. 351.

${ }^{41}$ Charles A. Hale, op. cit., p. 22.

${ }^{42}$ Lucas Alamán, Disertaciones, 1942, México, Jus, t. I, p. 127-8. 
de 1847 por las tropas norteamericanas era, tal vez, una forma de 'retribución divina' que conmemoraba la pavorosa insurrección de $1810 .{ }^{43}$

Don Lucas pensaba que el espíritu revolucionario -que pretendía la construcción de un ser humano y una sociedad nuevas prescindiendo de Dios y del pasado- era la más dolorosa marca de su tiempo. Los crímenes cometidos por Hidalgo en Guanajuato eran, en el fondo, una extensión más de lo que había sucedido en la Francia jacobina y un ejemplo patente de lo que se avecinaba en el futuro. Su actuación como estadista y líder del partido conservador estaría dirigida, precisamente, a evitar que este fantasma que recorría el mundo destruyera -en su versión liberal- el fundamento mismo de la nación mexicana (como de hecho sucedió en Francia). Defender a la Iglesia, de este modo, no sólo era una tarea de cualquier católico: era el supremo deber de todo patriota.

\section{La Iglesia y el Estado en la nueva nación}

Estudiar la carrera política de Alamán supone dar cuenta de los primeros treinta años de vida del Estado mexicano. Don Lucas estaba metido en todo: fue diputado, secretario de despacho y consejero de presidentes, jefes militares e incluso obispos; elaboró proyectos de ley sobre las más diversas materias, fundó escuelas e instituciones de beneficencia, y también fue un impulsor decidido de la industria como cimiento económico de la nación (para cuyo financiamiento fundó el Banco de Avío). Siendo nuestro tema su pensamiento religioso, sólo haremos una breve reseña de su labor política en torno a la cuestión del patronato y de su férrea afirmación del catolicismo como elemento esencial de la nueva y emergente nacionalidad mexicana. Como estadista, hay que subrayarlo, Alamán "no preconizó nunca la supremacía de la Iglesia, la construcción de la ciudad de Dios o la realización de alguna utopía clerical”, 44 pero siempre estuvo convencido de que los ataques

${ }^{43}$ Lucas Alamán, Historia de Méjico, 1942, México, Jus, t. II, p. 213.

${ }^{44}$ Jean Meyer, op. cit., p. 73. 
PABLO MIJANGOS

radicales a la propiedad y privilegios eclesiásticos llevarían a México a la más terrible discordia civil, y de que ésta sería el preludio de una nueva conquista extranjera, conducida esta vez por la vecina república protestante.

Para entender el primer punto, debemos tener en mente que uno de los más importantes debates que tuvieron lugar durante los primeros años de la república fue el relativo a los derechos del nuevo Estado mexicano frente a la Iglesia. ${ }^{45}$ Como sabemos, los papas del siglo XVI concedieron a la Corona española los beneficios del Regio Patronato Indiano -entre los que se incluía el derecho de presentar candidatos para los beneficios eclesiásticos, el control sobre las comunicaciones provenientes de Roma y la decisión final sobre el establecimiento de nuevas diócesis-en recompensa a sus esfuerzos por incorporar nuevas tierras al cristianismo. ${ }^{46}$ Las facultades provenientes del patronato fueron ejercidas por los reyes a lo largo de todo el período colonial, y una pregunta que surgió inmediatamente después de conseguida la Independencia fue si los nuevos gobiernos podrían ejercer dichas facultades también. Entre 1824 y 1832 no se pudo llegar a un consenso en esta materia. Mientras que los liberales sostuvieron la respuesta afirmativa, la Iglesia argumentó que el patronato no era un derecho inherente a la soberanía del Estado, sino un privilegio concedido a los monarcas españoles y nada más a estos. Esta última fue la posición defendida por Alamán, quien como ministro del gabinete de Anastasio Bustamante (1830-1832) señaló claramente que el Estado mexicano renunciaba a cualquier beneficio derivado del antiguo patronato. ${ }^{47}$ La opinión de Don Lucas respecto a esta materia era clara:

${ }^{45}$ Cfr. Michael P. Costeloe, Church and State in Independent Mexico. A Study of the Patronage Debate, 1821-1857, 1978, London, Royal Historical Society, p. 1-15.

${ }^{46}$ Guillermo Floris Margadant, La Iglesia ante el derecho mexicano. Esbozo histórico-jurídico, 1991, México, Miguel Ángel Porrúa, p. 128-31.

${ }^{47}$ John Lloyd Mecham, Church and State in Latin America, 1966, Chapel Hill, The University of North Carolina Press, p. 347. 
Pudo ser este [patronato] útil, cuando los príncipes verdaderamente cristianos, dispensaban á la iglesia una protección de que tenía necesidad, y ejercían las facultades que él les daba por las fundaciones que habían hecho y bienes con que las habían dotado: pero a fuerza de ensanchar los límites de esta protección, vino a ser una verdadera opresión, y cuando menos, poniendo al clero bajo la dependencia del gobierno civil, lo hizo adulador de éste. ${ }^{48}$

Su posición ultramontana hizo del ex-ministro Alamán uno de los blancos del gobierno radical de Valentín Gómez Farías (1833-1834). Unos días después de la llegada al poder de este último (como vicepresidente), Alamán fue acusado de haber participado en el asesinato de Vicente Guerrero, y la encarnizada persecución de la cual fue objeto lo llevó a esconderse durante dos largos años. En su ausencia, el partido liberal propuso una serie de reformas en las que no se limitaba a reclamar exclusivamente la continuación del patronato, tal como había hecho hasta 1832. Influidos por el pensamiento de José María Luis Mora -entonces consejero de Gómez Farías-, los congresistas radicales pensaron que atacar de frente la omnipresencia social de la Iglesia era el único modo de imponer cambios fundamentales en la vida política, económica y cultural de la nación. Y así, entre junio y diciembre de 1833, llevaron a cabo un primer ensayo de lo que sería la gran Reforma juarista de mediados de siglo: ${ }^{49}$ cierre de colegios eclesiásticos y de la Universidad (entonces Pontificia), secularización de las misiones, ley de provisión de curatos vacantes, incautación de bienes, expulsiones de obispos... Creadas por un grupo de intelectuales sin base política alguna, estas medidas fueron ampliamente rechazadas por la población, y el presidente Antonio López de Santa Anna se vio obligado a desmantelar rápidamente todo el edificio del gobierno liberal a principios de 1834.

\footnotetext{
${ }^{48}$ Lucas Alamán, Historia de Méjico, 1942, México, Jus, t. v, p. 837.

${ }^{49}$ Sobre la reforma de Gómez Farías, véase Michael P. Costeloe, La primera república federal de México (1824-1835), 1975, México, FCE, p. 371-412.
} 
PABLO MIJANGOS

Pese a las amenazas en su contra, don Lucas Alamán fue uno de los mayores críticos de esta experiencia reformista, a la que consideró “algo sólo comparable con la historia de Francia en la época desventurada del dominio de los jacobinos desde 1792 a $1795 " .50$ Dado que el Congreso de 1833 y los gobiernos estatales habían dado lugar a "todo cuanto el déspota oriental más absoluto en estado de demencia pudiera imaginar más arbitrario e injusto", 51 don Lucas propuso en 1835 la elaboración de un nuevo texto constitucional que cerrara la puerta de las instituciones a la demagogia del partido radical, le diera mayor unidad a la política del país e hiciera efectivas las limitaciones jurídicas al ejercicio del poder político, particularmente en lo relativo al respeto de las libertades de la Iglesia. ${ }^{52}$ Aunque el nuevo régimen centralista, consagrado en las Siete Leyes de 1836 (y modificado en buena medida en 1843), no supuso una solución a la inestabilidad crónica que vivía el país, durante casi diez años los debates en torno al patronato y a la reforma religiosa disminuyeron de intensidad. Alamán fue electo diputado y nombrado consejero de Gobierno en 1836, pero en 1841 prefirió retirarse temporalmente de la vida pública para atender sus negocios particulares. Este alejamiento no duraría mucho, pues en 1846 empieza a colaborar en el periódico El Tiempo y participa en la breve conspiración monarquista del general Mariano Paredes y Arrillaga.

La traumática derrota de México frente a Estados Unidos en 1847 hizo que la cuestión eclesiástica se encontrara nuevamente en medio del torbellino. Radicalizados aún más durante los años de la república centralista, los liberales consideraron que la Iglesia no había contribuido de modo suficiente a la defensa del territorio: si el Estado hubiera podido disponer abiertamente de sus capitales, el resultado de la guerra habría sido otro. En respuesta, Alamán señaló que el resultado de la guerra era una consecuencia más de los ‘desórdenes’ que habían acom-

50 Lucas Alamán, "Defensa del Ex-Ministro de Relaciones D. Lucas Alamán”, en Documentos diversos, t. III, p. 95.

${ }^{51}$ Lucas Alamán, Historia de Méjico, 1942, México, Jus, t. v, p. 791.

${ }^{52}$ Cfr. Pablo Mijangos y González, El primer constitucionalismo conservador: las Siete Leyes de 1836, tesis profesional, 2001, México, ITAM. 
pañado a México desde su independencia, provocados por el ataque liberal al 'edificio religioso y social' heredado de tiempos coloniales. Charles Hale sostiene, con toda razón, que la invasión norteamericana marcó un hito en el desarrollo del pensamiento político de Alamán. ${ }^{53}$ Si hasta entonces su postura había consistido en defender la libertas ecclesiae a toda costa, de aquel momento en adelante afirmaría una y otra vez que la Iglesia Católica era el alma misma de la nacionalidad mexicana. Don Lucas consideraba, en efecto, que para sacar al país de la catástrofe era imprescindible mantener la unidad en torno a la raíz católica de la nación, pues

En medio de un trastorno tan completo de todos los elementos de la sociedad, lo único que ha permanecido inmutable es la Iglesia, y esto debido a que ni el Congreso ni el gobierno han podido poner mano en su administración ni en la elección de sus ministros, habiendo resistido los obispos con admirable energía el ejercicio del patronato. ${ }^{54}$

Con esta idea en mente, Alamán comienza a escribir su monumental Historia de Méjico y en 1848 funda el partido conservador, cuyo primer principio sería "conservar la religión católica, porque creemos en ella, y [...] la consideramos como el único lazo común que liga a todos los mexicanos, cuando todos los demás han sido rotos, y como lo único capaz de sostener a la raza hispanoamericana, y que puede librarla de los grandes peligros a los que está expuesta”. ${ }^{55}$ Esto implicaba, por supuesto, "sostener el culto con esplendor y los bienes eclesiásticos, arreglar todo lo relativo a la administración eclesiástica con el Papa [...] e impedir por la autoridad pública la circulación de obras impías e

${ }^{53}$ Cfr. Charles A. Hale, "La guerra con Estados Unidos y la crisis del pensamiento mexicano”, en Secuencia, n 16, enero-abril 1990, p. 43-62.

${ }^{54}$ Lucas Alamán, op. cit., p. 836.

${ }^{55}$ Carta de Lucas Alamán a Antonio López de Santa Anna, 23 de marzo de 1853, citada por Francisco de Paula de Arrangoiz, México desde 1808 hasta 1867, México, Porrúa, 1974, p. 422. 
PABLO MIJANGOS

inmorales”. ${ }^{56}$ Para realizar estas ideas, Alamán suponía contar “con la opinión general [...] y la fuerza moral que da la uniformidad del clero, de los propietarios y de toda la gente sensata que está en el mismo sentido". ${ }^{57}$ Pese a la derrota de 1847, Alamán era todavía bastante optimista respecto al futuro de su programa, ya que la sociedad estaba marcada todavía por 'un profundo sentimiento religioso':

La depravación en materias religiosas, no ha pasado todavía de algunos individuos de la clase artesana de la capital y de algunas otras ciudades grandes: el pueblo, tranquilo y moderado nada pide, y contento con que se le dejen sus fiestas y regocijos, con que no se le grave con excesivas contribuciones, no tiene las pretensiones que escritos seductores han inspirado a algunos pueblos de Europa... todos esos elementos de los grandes males de la sociedad moderna, no han echado raíces entre nosotros; los malos periódicos son detestados y no son otra cosa que motivo de escándalo y horror para la población en general: esta conserva fuerte adhesión a las doctrinas religiosas que recibió de sus antepasados... ${ }^{58}$

Alamán no llegaría a ver los frutos de su obra. Nombrado nuevamente secretario de despacho a principios de 1853, el 2 de junio de ese mismo año don Lucas falleció en su casa de la ciudad de México, víctima de un terrible padecimiento pulmonar. El gobierno del general Santa Anna perdía con él a uno de sus ministros más brillantes, y el partido conservador a su líder moral indiscutible. No podemos saber qué pasó por la mente de aquel terciario franciscano durante sus últimos días. Sus 61 años de vida los había entregado a la defensa de la patria católica e hispánica de su juventud, y seguramente estaba consciente de que sus esfuerzos no habían llegado todavía a buen término. Quizá, viendo ya su debilidad manifiesta, encomendaría el futuro de

${ }^{56}$ Ibid.

${ }^{57}$ Ibid.

${ }^{58}$ Lucas Alamán, op. cit., p. 856. 
su patria a Quien verdaderamente la había creado, repitiéndose a sí mismo las últimas frases de su Historia

¡Quiera el Todopoderoso, en cuya mano está la suerte de las naciones, y que por caminos ocultos a nuestros ojos las abate o las ensalza según los designios de su Providencia, dispensar a la nuestra protección con que tantas veces se ha dignado preservarla de los peligros a que ha estado expuesta! ${ }^{59}$

\section{A modo de conclusión}

En uno de los más recientes estudios sobre Alamán, la historiadora Lourdes Quintanilla señala que la búsqueda de la unidad es el rasgo más característico de la obra intelectual y política de nuestro personaje. ${ }^{60}$ Hay que aclarar, sin embargo, que en Alamán la unidad es un concepto más teológico que político. La divergencia con sus enemigos liberales se da, justamente, en este difícil punto. Para éstos, como agudamente observa Jean Meyer, la Iglesia era un instrumento inigualable para la conservación del orden público y la moralización de las costumbres, y por ello consideraban que debía estar sometida a las políticas del Estado en todo momento. ${ }^{61}$ Veían en el cristianismo un catálogo de preceptos, y en su visión de una sociedad secular no cabía la idea de una religiosidad que fuera más allá del ámbito exclusivamente individual. Para Alamán, por el contrario, la unidad de la Iglesia -y no un corpus ético determinado- aparece como la expresión misma del mensaje cristiano. Leyendo con atención, vemos que en su obra la Iglesia es una realidad concreta que permite la unidad entre razón y fe, y entre Dios y los hombres. Gracia de la Providencia, es también una presencia humana que da forma y unidad al tejido social: de

${ }^{59}$ Idem, p. 879.

${ }^{60}$ Lourdes Quintanilla, El nacionalismo de Lucas Alamán, Guanajuato, Gobierno del Estado de Guanajuato, 1991, p.83-6.

${ }^{61}$ Jean Meyer, op. cit., p. 72. 
PABLO MIJANGOS

hecho, es la única salvaguarda frente a la amenaza extranjera y la desintegración política de la nación.

Moisés González Navarro tiene razón en afirmar que el pensamiento religioso de Alamán no se aleja ni un momento de la más estricta ortodoxia católica. ${ }^{62}$ Viendo en la Iglesia el 'cuerpo místico de Cristo', centra en ella sus esfuerzos y esperanzas. Por eso no debe extrañarnos que censure las prácticas religiosas -y morales- del pueblo y a la vez afirme el éxito de la evangelización y el 'profundo sentimiento religioso’ de la sociedad de su tiempo. Algunos han visto en esta contradicción un reflejo de su posición aristocrática o de sus oscuros recuerdos de Hidalgo. Sin descartarlo de antemano, debemos tener en cuenta, nuevamente, que la preocupación de Alamán no estaba en la transformación individual, sino en el establecimiento y defensa de una Iglesia visible. La creación de un hombre nuevo, ideal de todo movimiento revolucionario, es aborrecida por el espíritu conservador de Alamán. La renovación, de ser posible, no es fruto de los esfuerzos humanos. Aunque cree en los avances de la ciencia y piensa en términos de constituciones y desarrollo industrial, no deposita en ellas su proyecto para el porvenir: lo más importante es que el pueblo conserve su adhesión a la herencia cristiana de sus antepasados. Unos años después de su muerte, los liberales de la Reforma lucharían precisamente por hacer de la adhesión a la patria y el sacrificio por la república las máximas virtudes del ciudadano. ${ }^{63}$ El conflicto no pudo haber quedado definido de manera más exacta. Su desenlace... todavía no lo sabemos.

${ }^{62}$ Moisés González Navarro, op. cit., p. 53.

${ }^{63}$ David Brading, Los orígenes del nacionalismo mexicano, 1988, México, Era, p. 139-42. 